\title{
Las Escuelas Infantiles Mucipales (0-3 Años) Aproximación A Un Estudio De Calidad En Canarias
}

\author{
David Pérez-Jorge \\ Raquel Mena-Cruz \\ Ana Isabel González-Herrera
}

Departamento de Didáctica e Investigación Educativa,

Universidad de La Laguna, España

Josué Gutiérrez-Barroso

Departamento de Sociología, Universidad de La Laguna, España

Doi: 10.19044/esj.2017.v13n29p134 URL:http://dx.doi.org/10.19044/esj.2017.v13n29p134

\begin{abstract}
The panorama of kindergartens Canary, as a whole today, is uncertain due to lack of subsidies and as a result of the global crisis that took place in our country years ago. In addition, large cuts have been made and are still continuously used to make public administrations which affect sensitive way to education. Furthermore, we have analyzed the reality of municipal kindergartens of the Canary Islands. This analysis was done based on what we have considered to be a minimum quality criteria for the effective functioning of these services. Also, we have tried to catch a glimpse of the reality of these schools so as to offer the keys to a model of educational management. This however guarantees both the quality of service and the user's satisfaction.
\end{abstract}

Keywords: Kindergartens, Canary Islands, quality

\section{Resumen}

El panorama de las escuelas infantiles canarias, en su conjunto a día de hoy, no sólo es algo incierto por falta de subvenciones y por la vorágine de la crisis mundial acontecida, desde hace años en nuestro país, sino que además a esto se suma los grandes recortes que se han hecho y siguen haciendo las administraciones públicas y que afectan de manera sensible a la educación. Para intentar ir un poco más allá, hemos analizado la realidad de las escuelas municipales infantiles de Canarias, en base a lo que hemos considerado criterios mínimos de calidad para el funcionamiento eficaz de estos servicios. Hemos tratado de vislumbrar la realidad de dichas escuelas, a 
fin de ofrecer las claves de un modelo de gestión educativa, que garantice tanto la calidad del servicio como la satisfacción de los usuarios.

Palabras clave: Escuela infantil, Islas Canarias, calidad

\section{Introducción}

\section{Aproximación al Estado Actual del Primer Ciclo de Educación Infantil}

Los estudios en el ámbito de las ciencias humanas y sociales, así como el devenir de nuestra sociedad en la última década, han cambiado la idea que teníamos sobre la primera infancia, todo esto en un intento de mejorar la atención dada a los niños de esta etapa (Pérez-Jorge, 2010). El trabajo realizado hasta ahora en la primera infancia ha podido generar controversia, pero tal y como afirman Santín, Balart y Cabrales (2015, p.46), "los resultados muestran que los años de educación infantil impactan de forma positiva y significativa sobre el resultado futuros de los niños/as" tanto a nivel de desarrollo cognitivo como emocional.

El derecho de todos los niños a una educación de calidad desde su nacimiento, es algo que se debe garantizar, y tratar de perpetuar en el tiempo (Pérez-Jorge y Rodríguez, 2012). Esta educación exige de centros donde se respete, apoye, favorezca y se potencie el desarrollo integral de las capacidades de cada niño. Así los pequeños son los principales protagonistas de su propio desarrollo, con el apoyo y orientación del adulto, que favorece el desarrollo y madurez de los niños dándoles la oportunidad de potenciar sus capacidades y competencias, permitiéndoles descubrir y relacionarse con el mundo que les rodea (Pérez- Jorge, Barragán-Medero \& Molina-Fernández, 2017). El primer ciclo de Educación Infantil abarca pues desde los 0 a 3 años de edad, este periodo es tan crucial, que nos hablan con ahínco de los objetivos de escolarización del mismo, a cumplir en un determinado periodo, en el Monográfico Fundación Educación Ciudadanía (2008):

(...) Entre las metas a alcanzar por la Unión Europea para 2010, se encuentra el incremento de la escolarización en edades tempranas. En la Cumbre de Barcelona del 2002, se estableció el objetivo específico de conseguir una tasa de escolarización del $90 \%$ en niños de tres años y del 33\% para los niños menores de esa edad. España se encuentra entre los países de la Unión Europea que presenta las tasas de escolarización más elevadas a los tres años, con un $97 ' 5 \%$ frente a una media europea de 68'2\%. Sin embargo, no ocurre lo mismo en las edades inferiores a tres años donde no alcanzamos ese $33 \%$ establecido para el 2010, ya que según los datos del MEC, correspondientes al curso 
2006-2007, la tasa neta de escolarización ha sido del $27 \%$

(p.3).

Para poder entender la demanda y los tipos de centros que atienden a niños/as de estas edades (primer ciclo de Educación Infantil), se debe saber que todas las Escuelas Infantiles de Canarias, están gestionadas, en su mayoría por iniciativa privada. La iniciativa privada ofrece sus servicios como centros educativos a empresas privadas que brindan a sus trabajadores el servicio de asistencia a menores de 0 a 3 años, tales son los casos de empresas como JSP o el Hospital Universitario de Canarias. Además de la oferta privada existe una oferta pública, dependiente de la Consejería de bienestar Social, de Cabildos Insulares, de ayuntamientos o de ciertas ONGs y obras sociales de fundaciones como la Caixa.

La escolarización de niños de 0 a 3 años llevada a cabo desde las administraciones locales, a través de sus Escuelas Infantiles de titularidad municipal, suele ser directa o indirecta y se ofrecen como un servicio público. La educación pública trata pues de hacer de la educación un instrumento para el fomento de la igualdad, sobre todo desde la primera infancia, tal y como afirma, Pérez-Jorge (2010) y Pérez-Jorge (2010b), la escuela pública se caracteriza por su papel "compensador de desigualdades.

\section{Acercamiento a Las Leyes Que Regulan el Primer Ciclo de Educación Infantil (0-3 años)}

Para tratar de construir un abanico ordenado de las leyes que regulan y ordena el funcionamiento de este ciclo, desde los niveles más altos, hasta llegar a la concreción municipal, haremos un recorrido por las diferentes leyes, decretos y reglamentos. En la actualidad hablamos a nivel estatal de la Ley Orgánica de Educación (LOE), 2/2006 de 3 de mayo, como legislación básica para la regulación y ordenamiento de este ciclo.

Dentro de esta ley y de forma específica en sus principios generales se alude a que:

1. La etapa de educación infantil se ordena en dos ciclos. El primero comprende hasta los tres años, y el segundo, desde los tres a los seis años de edad.

2. El carácter educativo de uno y otro ciclo será recogido por los centros educativos en una propuesta pedagógica. (p.17167)

Haciendo un análisis de las leyes que, a nivel estatal, contemplan la existencia del ciclo y hablan incluso de su ordenación, áreas, contenidos, etc. se puede afirmar que la Ley Orgánica de Ordenación General del Sistema educativo (LOGSE) del 3 de Octubre de 1990, fue la que reconoció la relevancia de este ciclo, potenciando su implantación. Esta ley pese a que no concretó su desarrollo reconoció su carácter educativo y voluntario. Con la posterior Ley Orgánica de Calidad Educativa (LOCE) del 23 de Diciembre 
de 2002, este primer ciclo, fue reconocido como de carácter educativoasistencial. Con la Ley Orgánica de Educación (LOE) del 3 de Mayo del 2006, se vuelve hacer hincapié en el carácter educativo de este ciclo, desarrollándose, principalmente a partir de esta ley, la más importe red de centros y escuelas municipales de Educación Infantil. A modo de síntesis se puede observar en la Tabla 1 esta evolución del carácter y finalidad de este primer ciclo de la Educación Infantil.

Tabla 1. Comparativa entre LOGSE, LOCE y LOE en relación a la educación al $1^{\circ}$ ciclo de Educación Infantil

\begin{tabular}{|c|c|c|}
\hline LOGSE & LOCE & LOE \\
\hline $\begin{array}{l}\text { Se ordena en dos ciclos de } \\
\text { carácter educativo y } \\
\text { voluntario. }\end{array}$ & $\begin{array}{l}\text { Se ordena en dos ciclos: } \\
\text { SLẼ Educación Preescolar de } \\
\text { 0-3 años de carácter } \\
\text { educativo-asistencial. }\end{array}$ & $\begin{array}{l}\text { Se ordena en dos ciclos y } \\
\text { tiene un carácter educativo y } \\
\text { voluntario. }\end{array}$ \\
\hline $\begin{array}{l}\text { Finalidad: Desarrollo físico, } \\
\text { intelectual, afectivo, social y } \\
\text { moral. }\end{array}$ & $\begin{array}{l}\text { Finalidad: Desarrollo físico, } \\
\text { intelectual, afectivo, social y } \\
\text { moral. }\end{array}$ & $\begin{array}{l}\text { Finalidad: Desarrollo físico, } \\
\text { afectivo, social e intelectual. }\end{array}$ \\
\hline $\begin{array}{l}\text { Impartida por maestros } \\
\text { especialistas y otros } \\
\text { profesionales con la debida } \\
\text { cualificación en el } 1^{\circ} \text { ciclo. }\end{array}$ & $\begin{array}{l}\text { Impartida por profesionales } \\
\text { con la debida cualificación. }\end{array}$ & 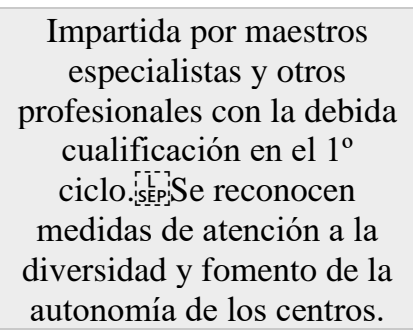 \\
\hline
\end{tabular}

Así mismo a nivel estatal, como ley que afecta sólo al segundo ciclo en cuanto a la organización, cualificación de sus profesionales, instalaciones, creación de centros, red de escuelas, de los órganos colegiados de gobierno, órganos de coordinación, etc., se estableció el Reglamento Orgánico de Centros (ROC) del 26 de Enero de 1996, en este caso no fue de aplicación directa al primer ciclo de Educación Infantil regulada a nivel autonómico por el decreto 201/2008 (Comunidad Autónoma de Canarias).

El Decreto 201/2008, de 30 de Septiembre, estableció los contenidos educativos y los requisitos de los centros que imparten el primer ciclo de Educación Infantil en la Comunidad Autónoma de Canarias, y cabe destacar que concreta que;

(...) uno de los fines destacados de la educación es, sin duda, el pleno desarrollo de la personalidad y de las capacidades cognitivas y afectivas y sociales de los niños y niñas. La ley orgánica $2 / 2006$, de 3 de mayo, de educación, regula, en el Título I, Capítulo I, la Educación Infantil, como una etapa única aunque dividida en dos ciclos, y establece en su artículo 14.7 que las Administraciones educativas determinarán los contenidos 
educativos del primer ciclo de la Educación Infantil, así como lo regularán los requisitos que hayan de cumplir los centros que impartan dicho ciclo. Por tanto, es competencia de esta Comunidad Autónoma para su ámbito de actuación regular el primer ciclo de Educación Infantil (p.19393).

A nivel de Canarias, la Resolución de 26 de mayo de 2017, establece el calendario escolar y dicta las instrucciones para la organización y desarrollo de las actividades de comienzo y finalización del curso 2017/2018, para los centros de enseñanzas no universitarias de la Comunidad Autónoma de Canarias, planteando las mejoras, a nivel insular, del funcionamiento de las mismas, recogiendo de forma específica; la acogida temprana, el horario de actividades escolares (5 horas diarias), flexibilidad en la entrada y salida de los niños ( 8 horas diarias de permanencia en el centro).

Además de dicho decreto, se debe tener en cuenta que cada centro a nivel particular, debe contemplar de forma amplia su propuesta pedagógica, que marca el devenir de su organización y funcionamiento, en cuanto a organización del centro, estructura del personal, ordenación de los espacios y dependencias, normas de funcionamiento, etc.

Teniendo en cuenta finalmente que existen las Escuelas Infantiles Municipales, tanto de gestión directa como indirecta, es importante resaltar que para el desempeño de dicha gestión éstos deben establecer Reglamentos, Ordenanzas, que regulan su gestión, además de cuestiones como precios públicos del servicio. Concretamente estas normativas y ordenanzas municipales tratan aspectos tales como:

1. Objeto y ámbitos de funciones (educación infantil 0-3 años).

2. Dependencia orgánica y funcional (comisión de la escuela, funciones del personal,...).

3. Servicios (educativos, de comedor,...).

4. Funcionamiento de la escuela/Reglamento de régimen interno (distintos horarios, tutorías, normas, control de faltas de asistencia, actividades exteriores...).

5. Solicitud, admisión y reserva de plazas (anexos con formularios).

6. Criterios de acceso y baremación de solicitudes.

7. Renuncia, baja y otras circunstancias relativas a la plaza.

8. Cuotas a abonar por los servicios prestados/Precios públicos (matrícula, cuotas mensuales/bonificadas o no).

9. Protección de datos de carácter personal. 


\section{Criterios Para el Establecimiento de Principios de Calidad en Escuelas Municipales de Educación Infantil}

Para abordar este apartado trataremos de establecer y definir lo que entendemos por calidad, para así, de esta manera poder concretar los principios e indicadores básicos que han de establecer los centros municipales de Educación Infantil para ofrecer un verdadero servicio de calidad. Tal y como recoge Azkona y Hoyuelos (2015):

(...) Cuando hablamos de calidad, debemos saber muy bien definirla y poner sobre la mesa los criterios que están involucrados en la propia definición...En estos últimos años, el concepto de calidad es uno de los más manidos y utilizados en todos los aspectos de la vida ("calidad de vida", "servicios de calidad", "calidad al cliente"...) y, por ende, también en el ámbito educativo. (p.158)

Para poder señalar que un centro es o no de calidad, se deben tener en cuenta los siguientes criterios:

a) La profesionalidad, esto supone es establecimiento y reconocimiento de una formación específica, con una titulación y unos años de formación que hace que no sólo quien trabaje en estas etapas tan tempranas tengan aptitudes para ello, sino que aún más importante si cabe, que posea actitudes varias para el desempeño de su profesión.

b) La estabilidad del personal, podría ser otro de los criterios de consecución de las escuelas. Aquellos profesionales que se encuentren con dignidad en su puesto de trabajo, bien remunerados de acuerdo a sus funciones y estudios, serán profesionales más estables que llevarán a cabo una labor educativa como consecuencia con más estabilidad y sin cambios constantes en las figuras de referencia de los niños, pieza clave de todo esto.

c) La importancia del proyecto común y del trabajo en equipo, ha de ser también un criterio fundamental. Sin dejar de lado que es una etapa educativa más, el Proyecto Educativo de Centro (PEC), así como la Propuesta Pedagógica de Centro y las programaciones de aula, deben guiar y marcar los pasos de un proyecto de trabajo común. Todo esto debe ser revisable, abierto, flexible y dinámico.

d) También se puede considerar el servicio de cocina, como un elemento más de calidad de una escuela de educación infantil. Aquellos centros que cocinan de manera propia, sin servicios externos, se estima que no sólo elaboran sino que cuidan más los alimentos.

e) Las medios humanos y materiales, en cantidad suficiente, y en categorías necesarias, nos remite a la condición de centro de mayor calidad frente otros que carecen de personal, o el que tienen realiza multitareas, muchas de ellas sin cualificación ni experiencia. 
f) El respeto por el ratio de niños por aula, debe ser el lógico y adecuado, más aún cuando está establecido y fijado por ley. En un centro que se superen el números de niños por aula, no se puede garantizar la calidad de la atención dada a los menores, debe mirarse si el personal y los medios son suficientes.

g) La coordinación de las escuelas con el entorno que le rodea, es otro indicador índice también de calidad del servicio prestado. Tal y como afirman Azkona y Hoyuelos (2015).

(...) La Educación Infantil pretende ser un recurso social y cultural para toda la Comunidad en la que está ubicado. Se relaciona con el pueblo, barrio o ciudad ofertando iniciativas de formación que favorezcan el desarrollo personal y el intercambio de las diversas generaciones. (p.164)

Estos criterios han sido destacados por Zabalza y Bereza (1996), en su libro "Calidad en la Educación Infantil", se atreve a ir más allá estableciendo incluso una dicotomía entre lo que podría ser criterio de calidad o no en una escuela de educación infantil; un dilema entre cuidar o educar. Hace referencia a la diferencia entre lo asistencial y lo educativo e insiste en la disposición de recursos humanos y materiales. Además destaca la importancia de la existencia de programaciones de aula y un proyecto común y educativo de trabajo. Entre sus argumentos insiste también en si se debería establecer diferencia entre lo público y lo privado; es decir, si debería formar parte del ámbito educativo público (las escuelas infantiles de 0-3 años) o por el contrario formar parte de una red de escuelas privadas, en este sentido plantea muchas dudas sobre lo que sería realmente coherente. Así mismo, divaga entre el derecho al trabajo de los padres y el derecho de atención a los niños pequeños en horas y forma adecuada, los padres tienen el derecho de mantener la conciliación entre su vida familiar y laboral, pero debido a las jornadas laborales existentes en los últimos tiempos, los niños deben pasar más horas de lo establecido por normativa en la escuela infantil, cuestionándose la calidad de un centro si oferta más horas de los establecido por favorecer a sus usuarios.

Zabalza y Bereza (1996) habla de la "calidad del diseño", centrado su propuesta en el carácter público o privado, de las mismas. En este sentido apuesta por escuelas verdaderamente públicas que reciban subvenciones del estado. En relación a la calidad de los resultados este autor hace una importante apreciación, al hablar de poder trabajar desde edades temprana para detectar posibles dificultades en los menores. Esto sería lo ideal para trabajar, desde su detección anticipada, los déficits o dificultades de aprendizaje, este abordaje de las dificultades permitiría paliar muchos de las necesidades educativas derivadas de dichos déficits o dificultades. 
En definitiva, entre los criterios de calidad que se pueden fijar hoy en día para la mejora de las escuelas municipales de Educación Infantil, son múltiples y variados, pero todos se concretan en dimensiones fundamentales como la personal, profesional, y organizativa.

A modo de síntesis pues, y llegados a este punto, nos planteamos la necesidad de conocer la realidad del primer ciclo de la Educación Infantil en la Comunidad Autónoma de Canarias y más concretamente a nivel Municipal. Con esta intención se ha realizado un estudio de interés, que se ha concretado en los siguientes objetivos:

1. Conocer el mapa y estado actual de las escuelas infantiles municipales de Canarias.

2. Analizar la manera que se ocupan en las distintas escuelas la parte educativa de 0-3 años.

3. Identificar los déficits presentes en las diferentes escuelas municipales infantiles de Canarias.

4. Establecer propuestas para la mejora de la calidad de los centros educativos en el periodo de 0 a 3 años.

\section{Método}

\section{Muestra}

En este estudio han participado un total de 18 directores/coordinadores de Escuelas infantiles municipales de toda Canarias ( $1^{\circ}$ ciclo de educación infantil 0-3 años); tanto de la provincia de Santa Cruz de Tenerife como de las Palmas de Gran Canaria. Además de 4 directores/coordinadores de centro que participaron en una entrevista.

Tabla 2. Total de Escuelas Infantiles Municipales en Canarias

\begin{tabular}{|c|c|c|c|c|c|c|c|}
\hline Islas & $\begin{array}{c}\text { Las } \\
\text { Palmas }\end{array}$ & $\begin{array}{c}\mathrm{La} \\
\text { Gomera }\end{array}$ & $\begin{array}{c}\text { El } \\
\text { Hierro }\end{array}$ & Lanzarote & Fuerteventura & $\begin{array}{c}\mathrm{La} \\
\text { Palma }\end{array}$ & Tenerife \\
\hline $\begin{array}{c}\mathrm{N}^{\mathrm{o}} \\
\text { escuelas }\end{array}$ & 27 & 6 & 2 & 3 & 5 & 7 & 31 \\
\hline
\end{tabular}

Tabla 3. Número de escuelas infantiles municipales por municipios en Santa Cruz de Tenerife

\begin{tabular}{|c|c|}
\hline MUNICIPIO (Santa cruz de Tenerife) & $\mathrm{N}^{\circ}$ Escuelas \\
\hline Adeje & 1 \\
\hline Arafo & 0 \\
\hline Arico & 0 \\
\hline Arona & 2 \\
\hline Buena vista del Norte & 0 \\
\hline Candelaria & 1 \\
\hline El Rosario & 2 \\
\hline El Sauzal & 1 \\
\hline El Tanque & 1 \\
\hline Fasnia & 0 \\
\hline
\end{tabular}




\begin{tabular}{|c|c|}
\hline Garachico & 1 \\
\hline Granadilla de Abona & 1 \\
\hline Guia de Isora & 2 \\
\hline Güimar & 0 \\
\hline Icod de los vinos & 1 \\
\hline La Guancha & 1 \\
\hline La Matanza de Acentejo & 1 \\
\hline La Orotava & 2 \\
\hline La Victoria de Acentejo & 0 \\
\hline Los Realejos & 2 \\
\hline Los Silos & 1 \\
\hline Puerto de la Cruz & 0 \\
\hline San Cristóbal de La Laguna & 6 \\
\hline San Juan de la Rambla & 1 \\
\hline San Miguel de Abona & 1 \\
\hline Santa cruz de Tenerife & 2 \\
\hline Santa Úrsula & 0 \\
\hline Santiago del Teide & 0 \\
\hline Tacoronte & 1 \\
\hline Tegueste & 0 \\
\hline Vilaflor & 0 \\
\hline El Pinar & 0 \\
\hline La Frontera & 1 \\
\hline Valverde & 1 \\
\hline Agulo & 1 \\
\hline Alajeró & 1 \\
\hline Hermigua & 1 \\
\hline San Sebastián de la Gomera & 1 \\
\hline Valle Gran Rey & 1 \\
\hline Vallehermoso & 1 \\
\hline Barlovento & 0 \\
\hline Breña Alta & 1 \\
\hline Breña Baja & 1 \\
\hline El Paso & 0 \\
\hline Garafía & 0 \\
\hline Los Llanos de Aridane & 1 \\
\hline Puntagorda & 1 \\
\hline Puntallana & 1 \\
\hline Santa Cruz de la Palma & 0 \\
\hline Tazacorte & 0 \\
\hline Tijarafe & 1 \\
\hline Villa de Mazo & 1 \\
\hline
\end{tabular}


Tabla 4. Número de escuelas infantiles municipales por municipios en Las Palmas de Gran Canaria

\begin{tabular}{|c|c|}
\hline MUNICIPIO (Las Palmas de Gran Canaria) & $\mathrm{N}^{\circ}$ Escuelas \\
\hline Agaete & 0 \\
\hline Agüimes & 1 \\
\hline Artenara & 0 \\
\hline Arucas & 0 \\
\hline Firgas & 0 \\
\hline Gáldar & 1 \\
\hline Ingenio & 2 \\
\hline La Aldea de San Nicolás & 0 \\
\hline Las Palmas de Gran Canaria & 11 \\
\hline Mogán & 1 \\
\hline Moya & 0 \\
\hline San Bartolomé de Tirajana & 3 \\
\hline Santa Brígida & 1 \\
\hline Santa Lucia de Tirajana & 4 \\
\hline Santa María de Guía & 0 \\
\hline Tejeda & 0 \\
\hline Telde & 0 \\
\hline Teror & 0 \\
\hline Valsequillo & 1 \\
\hline Valleseco & 1 \\
\hline Vega de San Mateo & 1 \\
\hline Arrecife & 0 \\
\hline Haría & 0 \\
\hline San Bartolomé & 1 \\
\hline Teguise & 1 \\
\hline Tias & 1 \\
\hline Tinajo & 0 \\
\hline Yaiza & 0 \\
\hline Antigua & 0 \\
\hline Betancuria & 0 \\
\hline La Oliva & 1 \\
\hline Pájara & 4 \\
\hline Puerto del Rosario & 0 \\
\hline Tuineje & 0 \\
\hline
\end{tabular}

\section{Instrumento}

Para la realización de este estudio se utilizó un cuestionario ad hoc, tomando como referencia las dimensiones extraídas del análisis de las diferentes ordenanzas municipales que regulan el funcionamiento de las escuelas infantiles en el periodo de 0 a 3 años. El cuestionario contó con un total de 41 ítems, contando con los datos de identificación, que se ordenaron en torno a 3 dimensiones específicas; a) Ámbito de Gestión, b) Ámbito Educativos, c) Ámbito organizativo. 
Los ítems fueron principalmente de respuesta dicotómica, de respuesta abierta y de valoración en una escala de 1 a 5 donde 1 expresaba el menor grado de acuerdo y 5 el máximo grado de acuerdo.

En cuanto a las dimensiones tratadas en el cuestionario, destacan; los datos de identificación del centro que fueron: nombre, año de creación, edades que atienden,..., datos de gestión: directa o indirecta, uso de servicios externos,..., datos educativos; disposición de PEC, de programaciones de aula, tratamiento de neae,..., y por último datos organizativos; número de aulas, horario del centro, control de faltas de asistencia del menor al centro,...

En referencia a las dimensiones de la entrevista; se preguntó acerca del personal y su número, sobre el perfil de las familias atendidas, la gestión, filosofía del centro, opinión personal sobre el ciclo de 0-3 años en Canarias, sobre el carácter asistencial o no de esta etapa, y por último las expectativas hacia este estudio.

\section{Procedimiento}

La recogida de información se realizó mediante un procedimiento de encuestación telefónica y vía web, confirmando con el primer procedimiento cuestiones que no estaban claras o no se hallaban en la web de la Escuela Municipal. Una vez confirmada la existencia o no de escuela infantil pública en el municipio contactado, se procedió a contactar con los directores o coordinadores para llevar a cabo por encuesta telefónica. Además y mediante un procedimiento de selección aleatoria se procedió a seleccionar un total de 4 directores de centros para la realización de una entrevista semiestructurada. Para la identificación de las respuestas de los participantes de en la entrevista se utilizó el código Pn donde "P" se refiere a participante y " $n$ " al número de participante que responde.

\section{Resultados}

En este estudio que nos compete, han respondido a nuestros cuestionarios de dimensiones de calidad, un total de 18 centros o escuelas municipales de educación infantil. De entre estas 18 escuelas, llama la atención que tan sólo 4 escuelas infantiles fueran de la provincia de Las Palmas de Gran Canarias y 14 de la Provincia de Santa Cruz de Tenerife, aunque viendo la tabla de resultados de las escuelas censadas en una y otra provincia (ver Tabla 2), se entiende el hecho de que en Santa Cruz de Tenerife participaran más en tanto en cuanto, posee muchas más escuelas que Las Palmas. Tal y como se aprecia en la Figura 1, en la provincia de Santa Cruz de Tenerife se han censado un $78 \%$ del total de Escuelas Infantiles de Canarias frente al $22 \%$ de escuelas censadas en la provincia de Las Palmas de Gran Canaria. 


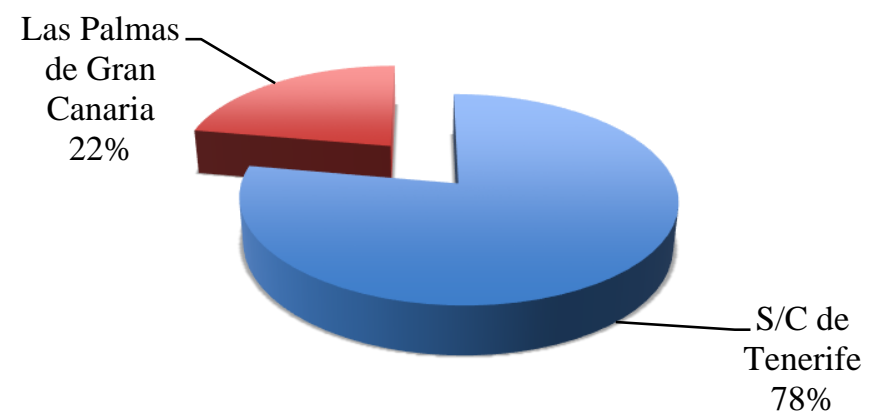

Figura 1. Distribución de las escuelas municipales de educación infantil por provincia

Respecto a los años de funcionamiento, tal y como se aprecia en la Figura 2, casi la mayoría lleva una media de 5 años, mientras que unas pocas llevan más de 10 años. Esto deja entrever, que aunque ya existían algunas escuelas infantiles de titularidad municipal desde hace años, han sido en los últimos cuando más ha proliferado su creación:

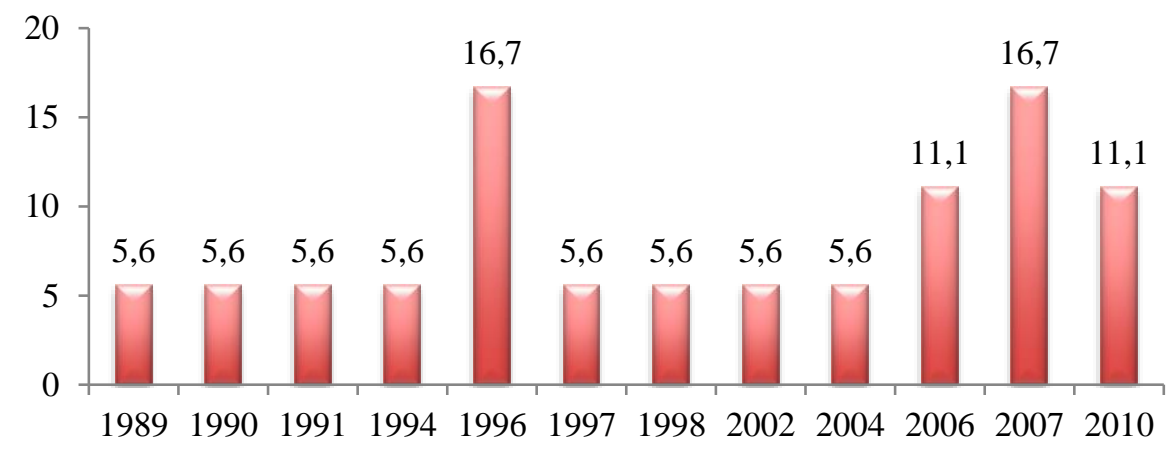

Años

Figura 2. Años de funcionamiento

De entre las edades de los alumnos que son atendidos, son las que marcan las normativas y decretos que regulan esta etapa; la mayoría de escuelas trabajan con alumnos cuyo rango de edad se encuentra entre los 4 meses y los 3 años. Solo algunas escuelas son mixtas con solo un aula de alumnos con edades mezcladas y muy pocas atienden solo a niños de 1-3 años, y no atienden a bebés $(5,6 \%)$.

Tabla 5. Edades que se trabajan

\begin{tabular}{|c|c|c|}
\hline \multicolumn{2}{|c|}{ Intervalos de edad } & Porcentaje \\
\hline & de 4 meses a 3 años & 77,8 \\
\cline { 2 - 3 } & de 12 meses a 3 años & 16,7 \\
\hline de 9 meses a tres años & 5,6 \\
\hline
\end{tabular}

En lo que se refiere al número de trabajadores, hemos de decir que 
varía en función del tamaño del centro, y del presupuesto que se destina anualmente para el funcionamiento de las escuelas. En el caso de las empresas que las gestionan, suele estar estipulado en el pliego de condiciones del concurso público, y en el caso de gestión directa esas plazas han debido salir a concurso público (oposición), en este último caso se ha podido constatar que las escuelas municipales dependientes directamente de los ayuntamientos poseen menor número de trabajadores que los que por normativa deberían tener. De esta manera se ha podido constatar que varían en cantidad desde los centros que poseen 14 trabajadoras, hasta centros que poseen tan sólo cuatro trabajadoras, lo cual nos hace pensar que puede ser un centro con pocas unidades de aula o en el que escasean los recursos humanos. Cuando en la entrevista personal, se preguntó a la dirección del centro si el hecho de ser de gestión directa afecta a la calidad del servicio, llamó la atención que P1 resaltara que " desde mi ayuntamiento se llevan escuelas tanto de gestión directa como indirecta y he de reconocer que los problemas reales de personal lo tenemos en las escuelas de gestión directa y no tanto en las gestionadas por empresas", P2 “ la administración exige el cumplimiento de la ley y de la normativa cuando ni el propio ayuntamiento respeta las ratios profesor alumno". En este sentido todos los coordinadores de centros de gestión directa (P2, P3, P4) entrevistados, coincidieron en la necesidad de tener más personal.

Respecto a las categorías profesionales, presentes en los centros de estas características, hemos observado la existencia de una amplia variabilidad de categorías profesionales; bien por el tamaño del centro, bien por el número de niños con el que cuentan, necesitan más de unas categorías que de otras, para ello presentamos en la figura de la 3 a la 7 los cinco grandes grupos de categorías profesionales que se observaron.

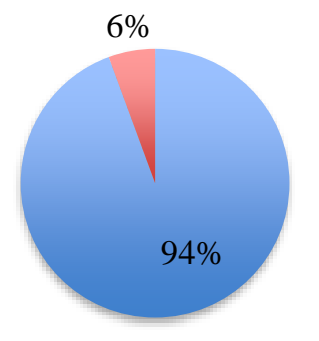

Figura 3. Categoría profesional grupo 1

$$
\begin{aligned}
& \text { Maestra de } \\
& \text { educación } \\
& \text { infantil } \\
& \text { Técnico } \\
& \text { superior }
\end{aligned}
$$

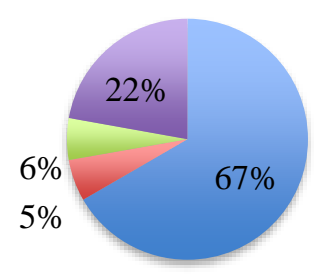

$$
\begin{aligned}
& \text { Técnico } \\
& \text { superior } \\
& \text { Psicopedago } \\
& \text { ga. }
\end{aligned}
$$

Figura 4. Categoría profesional grupo 2 


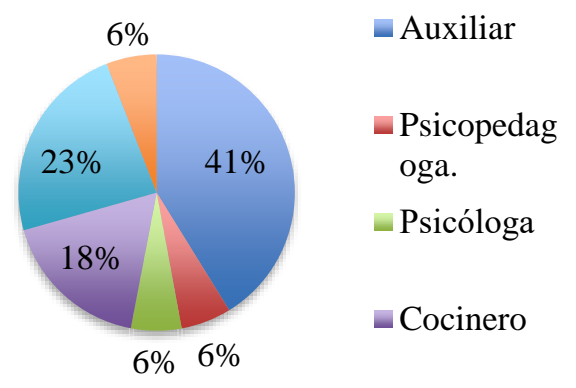

Figura 5. Categoría profesional grupo 3

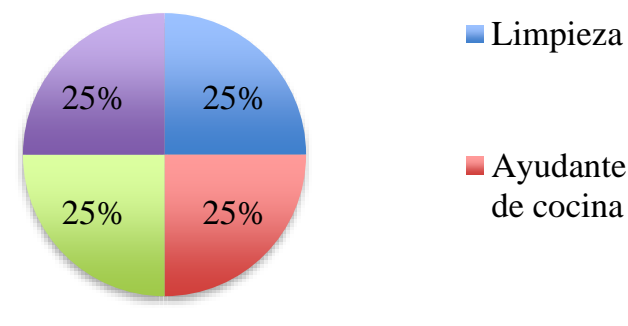

Figura 7. Categoría profesional grupo 5.

El perfil socioeconómico de las familias es medio, medio-alto, tal y como se puede observar en la Figura 8. Los usuarios de estos servicios no suelen ser familias de pocos recursos o de nivel socioeconómico bajo, que no puedan pagar una escuela infantil privada, tal y como cabría esperar. Las familias con ingresos medio-altos, acceden también como usuarios frecuentes de las escuelas infantiles municipales.

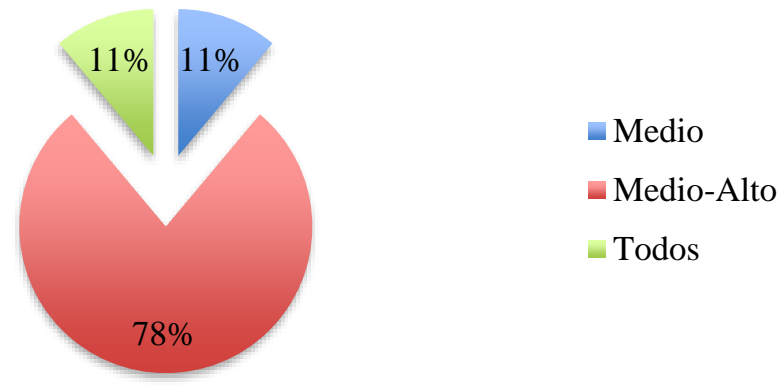

Figura 8. Perfil socieconómico de las familias

De los años de servicio que llevan las escuelas se deriva claramente, la permanencia de estos servicios en el tiempo y la proliferación, sobre todo 
en los últimos años, de escuelas de nueva creación.

Casi todas las escuelas fueron creadas con el fin de escuelas infantiles (15 del total de 18), solo 3 fueron creadas con otro fin.

La gestión de las escuelas es tanto directa, por parte de los propios ayuntamientos, con personal propio de la administración local, como indirecta, por parte de empresas que ponen a su personal. Si se observa la Figura 9 se puede apreciar que en Canarias la mayoría de las Escuelas Infantiles municipales son de gestión directa.

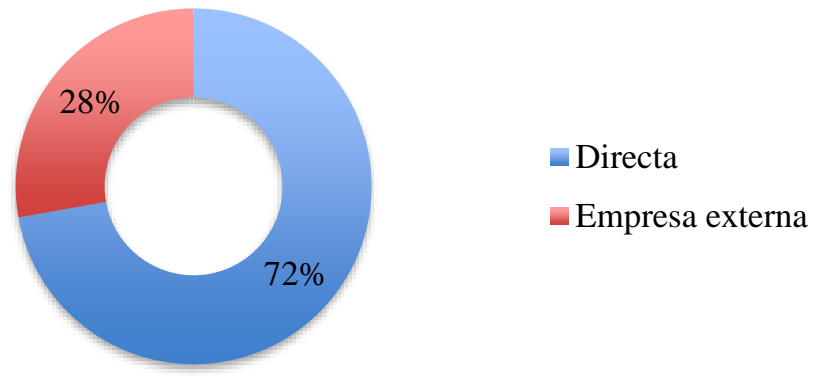

Figura 9. Gestión de la Escuela

La mayoría de las escuelas, regulan su funcionamiento a través de una ordenanza municipal, que no sólo trata de regular los precios públicos de servicio en algunas, sino que se va más allá, regulando el régimen interno de funcionamiento, funciones y tareas del personal, las normas del centro, PEC, etc.

La mayoría de las Escuelas Infantiles disponen dicha ordenanza de regulación de del servicio desde su año de creación, hecho que no es de extrañar ya que es una condición obligatoria para la puesta en marcha de una Escuela Infantil de gestión directa.

Tabla 6. Años de la ordenanza

\begin{tabular}{|c|c|c|}
\hline \multicolumn{2}{|c|}{ Año de la ordenanza } & $\%$ \\
\hline \multirow{4}{*}{} & 1989 & 5,6 \\
\cline { 2 - 3 } & 1996 & 5,6 \\
\cline { 2 - 3 } & 1997 & 5,6 \\
\cline { 2 - 3 } & 2003 & 11,1 \\
\cline { 2 - 3 } & 2004 & 11,1 \\
\cline { 2 - 3 } & 2006 & 11,1 \\
\hline & 2007 & 5,6 \\
\hline & 2012 & 38,9 \\
\hline
\end{tabular}

El copago, entendiendo cuota de abono compartida por usuarios y ayuntamiento, es lo más usual en estas escuelas, siendo casi la mitad de las 
mismas las que apuestan por este sistema de financiación. Son muy pocos los de usuarios en los que los servicios sociales de los ayuntamientos estiman cuota cero $(3 \%)$.

El uso de servicios externos, es una necesidad en determinadas escuelas, porque las funciones del personal educativo con el que cuenta, no llega a cubrir las necesidades del servicio. Un total de 13 escuelas cuentan con servicios externos; de entre estos servicios los más usados están los servicios de catering, de lavandería y de mantenimiento y limpieza. Entendemos que el uso de servicios externos en las escuelas, es una práctica muy usual en las mismas, este tipo de servicios fueron considerados como de calidad por parte del personal del centro, así P1 y P3, explicaban que "en el pliego de condiciones que se le da a la empresa, para acceder a gestionar el servicio, se tiene que detallar todo tipo de aspectos en relación a la comida, el trasporte, etc., de forma tan minuciosa, que no debe ser por ello sinónimo de no calidad, que está todo muy controlado". Teniendo en cuenta que P1 y P3 tenían tanto escuelas de gestión directa como indirecta, llama la atención que los sujetos P2 y P4 (coordinadores de escuelas de gestión directa), consideraran sin embargo que "lo mejor es cocina propia, en la que ves cómo se elaboran los alimentos, como se manipulan, se trabaja menos cantidad de comida".

A colación con este criterio, podemos presentar el resultado sobre el uso de cocina o catering en estas escuelas. De manera casi exacta, la mitad de los centros encuestados poseían catering, y la otra mitad cocina propia.

Solo algunas escuelas indicaron su presupuesto anual, con los datos dispuesto podemos advertir existe una importante variabilidad en los presupuestos, que va desde 53.000 euros, hasta las escuelas que han dispuesto de un presupuesto anual de 566.000 euros anuales. Por tanto, consideramos que los gastos por niño, aunque también en personal (según convenios colectivos, etc.), material (en función del tamaño de la escuela, a mayor tamaño más gastos), varía mucho de una escuela a otra.

A este presupuesto se une la tabla de subvenciones, en la cual claramente se deja entrever, que la llegada de la crisis ha supuesto una merma, y un recorte radical en los presupuestos y subvenciones de este primer ciclo de educación infantil. Ninguna escuela recibe del Gobierno Central ayuda alguna para costear este ciclo de educación infantil. Para confirmar estos datos ver Tabla 7:

Tabla 7. Reciben o no subvenciones

Reciben subvenciones

$\%$

\begin{tabular}{|c|c} 
No & 100 \\
\hline $\mathrm{Si}$ & 0
\end{tabular}

Destacar que todos los centros participantes disponían de Proyecto Educativo y programaciones de aula, lo que evidenció el interés por cumplir 
las normativas vigentes en materia educativa de este ciclo. Si bien P1, creía que "en Canarias en este ciclo debería haber más controles, tanto en la pública como en la privada y así más líneas de intervención, por ejemplo a través de la gratuidad de este ciclo", P2 consideró que "no debería haber distinción entre una y otra, sino que la gestión de ambas fuera adecuada". Por otro lado, P3 consideró que "las escuelas municipales públicas cumplen más con los requisitos establecidos por decreto y priman más lo educativo, que las privadas". P4 afirmó que "se hace necesario revalorizar esta etapa educativa en general, que poco a poco han ido dejando de lado".

Respecto a las opiniones sobre el criterio asistencial vs educativo de la educación infantil, se observó una coincidencia de todos los participantes, que consideraron necesario "reafirmar el carácter educativo, porque aún hay mentalidades con carácter asistencial, que hay que tratar de cambiar, con hechos, con realidades como las maestras del segundo ciclo que agradecen la manera en la que llegan estos niños a sus centros, cuando pasan al segundo ciclo (competencialmente, evolutivamente, psicomotrizmente,...)" P1, P2, P3 y P4.

En lo referente al estilo educativo, casi todas las escuelas coincidieron en que sus estilos se basaban en "rutinas centradas en el juego, en la globalización, en el aprendizaje constructivo, en participación activa, y en donde esté la naturaleza también como medio de aprendizaje" (P2), (P3). Asimismo consideraban que "con este estilo educativo permiten acceder a los niños en estas edades tempranas, al conocimiento de una manera muy natural, pero siempre a través de rutinas, y teniendo en cuenta el carácter abierto, flexible, dinámico, funcional, revisable y con intencionalidad educativa, de este ciclo" (P1), (P4).

La mayoría de las escuelas realizaban tutorías con las familias, elemento este, que dejó entrever que son escuelas que se renuevan, que intercambian información con los padres, y que consideran a éstos como un recurso educativo, social y cultural fundamental para el éxito de la formación de los alumnos.

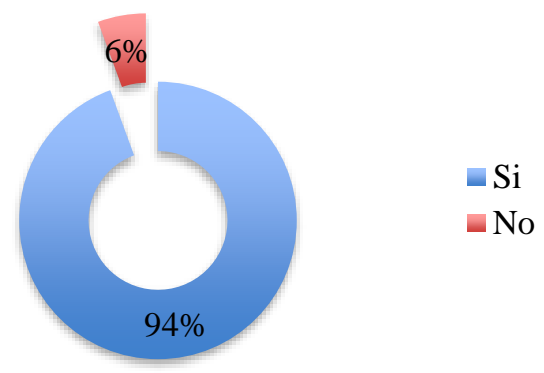

Figura 10. Sistema de tutorías con las familias 
En relación a la respuesta a los alumnos con necesidades educativas, se ha observado que casi todos los centros se han topado con alumnos con estas características. Casi todos los centros manifestaron haber tenido más de un caso, aunque muchos no han llegado a ser diagnosticados durante su permanencia en este ciclo. En este sentido los profesores que han tenido alumnos de estas características han intentado paliar o tratar los indicios las necesidades educativas derivadas del trastorno, déficit o dificultad, ver Figura 11. Estos alumnos no se han dejado de lado y han recibido apoyo educativo y profesional por parte de sus profesores, e incluso en algún caso por parte de equipos multidisciplinares de los centros educativos de zona. También de igual manera han sido tratadas las dificultades de aprendizaje en estos centros, aunque "de forma intuitiva y desde la experiencia con otros casos" (P3).

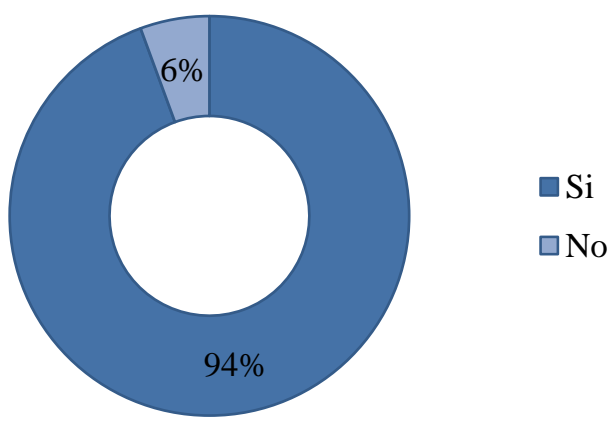

Figura 11. Tratamiento de las neae

La transición desde las escuelas infantiles municipales hacia los colegios de la zona (en donde los alumnos pasan de este ciclo al siguiente, $2^{\circ}$ ciclo de educación infantil), es un momento muy destacado y relevante para el profesorado de primer ciclo de educación infantil, casi siempre, si el centro receptor lo pide, hay voluntad de colaborar aportando información y los informes acerca de los niños que se derivan, lo vemos mejor en los porcentajes de la Tabla 8:

Tabla 8. Continuidad con los centros escolares de la zona

\begin{tabular}{|c|c|c|}
\hline \multirow{2}{*}{ Continuidad $2^{\circ}$ ciclo } & $\mathrm{Si}$ & $\%$ \\
\hline & $\mathrm{No}$ & 77,8 \\
\hline
\end{tabular}

Ahora bien con otras áreas de gestión municipal, cuyos servicios están directamente relacionados con la escuela, la realidad es distinta, siendo casi inexistente la relación y coordinación, por ejemplo, con los centros de 
salud de la zona. Esta cuestión resulta fundamental, para el control de los propios niños por parte del pediatra, y recomendaciones posibles, charlas, etc., de las que se podrían beneficiar las escuelas municipales y por ende los padres y niños escolarizados en las mismas, ver Figura 12.

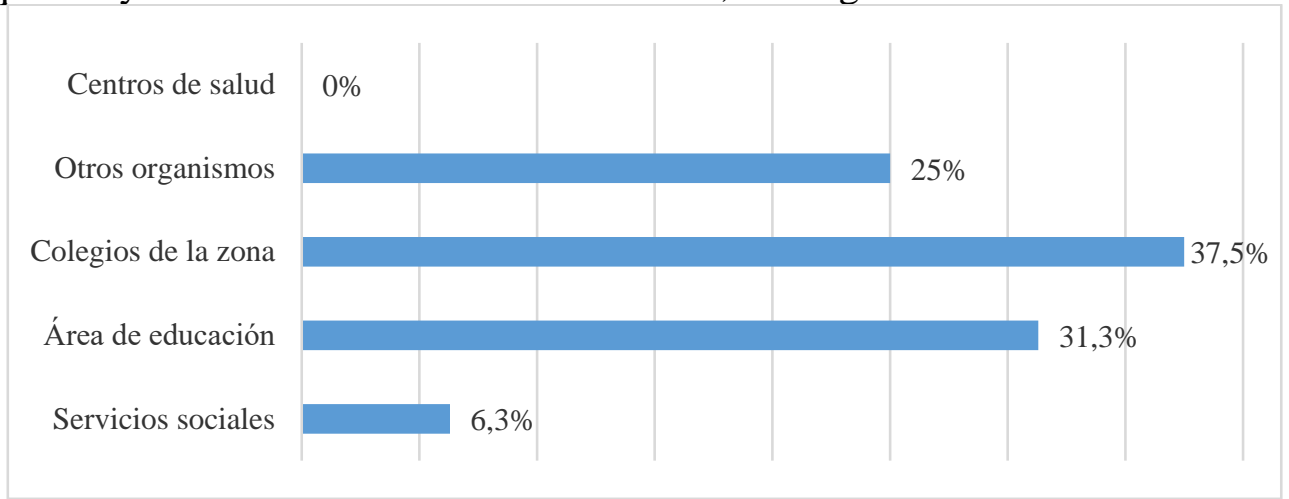

Figura 12. Coordinación con dependencias del ayuntamiento

En lo referente al número de alumnos por aula, se observaron datos muy distintos en función del centro, del tamaño del edificio, de las unidades de aula, etc. Si bien habían centros que respetaban la ratio establecida por el decreto 201/2008; de 8 niños en el aula de bebés, 13 niños en el aula de 1-2 años, y finalmente 18 en el aula de los mayores, de 2-3 años, otros centros en función de sus recursos, manifestaron permitir hasta 16 niños en bebés, 18 en 1-2 años e incluso 27 en 2-3 años. Se ha observado que un número importante de centros no cumplen con lo establecido en la legislación Canaria.

Más de la mitad de los centros ofrecía servicio de merienda, esto algo fundamental para la conciliación de la vida laboral-familiar, este hecho evidenció que se daba un incumplimiento de la norma de permanencia de los menores en los centros (un menor de 0-3 años, no debe pasar en un centro más de ocho horas seguidas; decreto 201/2008, Capitulo III, Artículo 15). Por ello el criterio de permanencia; resultó ser un arma de doble filo ya que al deber cumplir esta norma, y dado que los centros ofrecen horas de permanencia, es frecuente que los menores pasen más horas de las debidas en una escuela infantil.

En lo referente al horario de atención a las familias, son varios los horarios y diferenciados que se presentan tal y como vemos a continuación:

Tabla 9. Horario de atención a las familias

\begin{tabular}{|c|c|c|}
\hline & & $\%$ \\
\cline { 2 - 3 } & Mañana & 11,1 \\
\cline { 2 - 3 } & Tarde & 11,1 \\
\cline { 2 - 3 } & Mañana y tarde & 22,2 \\
\hline
\end{tabular}


El horario de los centros tal y como muestra en la Figura 13, deja claro, que la mayoría de los centros participantes tenían horario ampliado desde las 7:00 de la mañana y hasta las 17:00 de la tarde, esto favorece la permanencia prolongada de los menores en los centros.

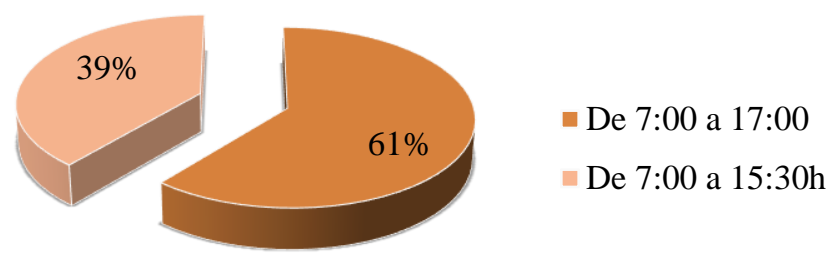

Figura 13. Horario de los centros

Respecto a la apertura del centro en periodos vacacionales, la mayoria contestó que si, el hecho de abrir en periodos como agosto, navidad, etc es muy frecuente, aunque se observó que numerosos centros cerraban en agosto concentrando los periods vacacionales de sus trabajadores en este mes.

Al hablar de la comisión de la escuela infantil, nos referimos al equipo de gobierno, formado por concejales, secretarios, funcionarios, etc, que se solían reunir en momentos clave para la gestión de la escuela, esto es; baremación de listas de admitidos, llegada de subenciones, retirada de plaza a un menor por faltas injustificadas, etc. Esta comisión necesaria para el funcionamiento de la escuala municipal infantil, se guiaba y apoyaba en la ordenanza municipal, incluso muchos de sus integrantes la trabajaban y modificaban si era necesario, en ocasiones estaba formada por el alcalde, concejalía dependiente de educación, directoras del centro, e incluso por trabajadoras sociales y por responsables de los menores. Mas de la mitad de los centros de este estudio disponían de dicha comisión, ver Figura 14.

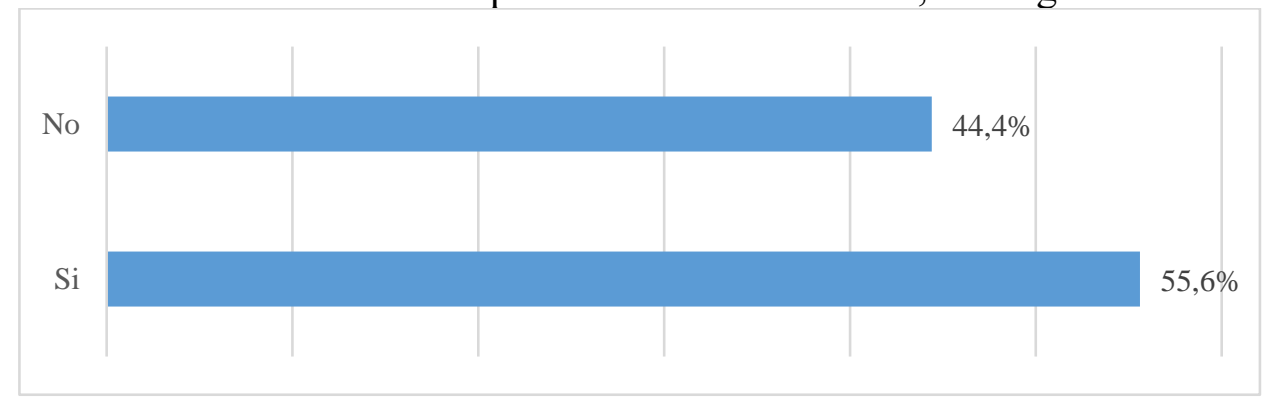

Figura 14. Comisión de la Escuela Infantil. 
Los procesos de coordinación con la concejalía que lleva gestiona la escuela municipal infantil, fueron insuficientemente valorados, casi tres cuartas partes de los centros manifestaron que no existía tal coordinación efectiva.

Casi en la mayoría de los centros participantes $(88,9 \%)$ se controlaba la asistencia del menor al centro, la inasistencia suponía la pérdida del servicio en favor de otros menores que lo habían solicitado. La ordenanza regulaba el servicio y recogía la inasistencia (más de 20 faltas) injustificada reiterada y consecutiva como causa de pérdida de la plaza.

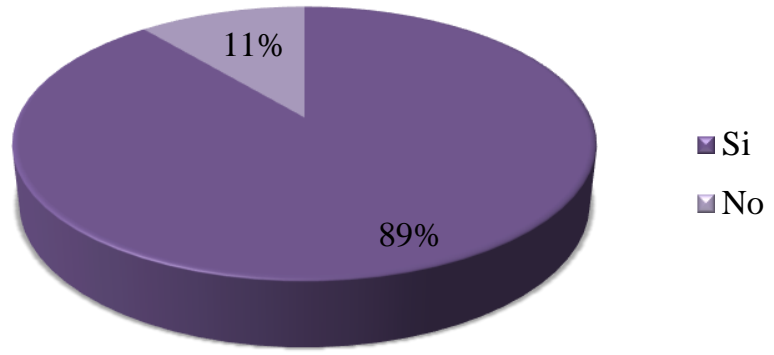

Figura 15. Control de faltas de asistencia de los menores

\section{Discusión y Propuestas}

Llegados a este punto y centrándonos en los aspecto fundamentales para la determinación de escuelas infantiles municipales de calidad, consideramos que cuando hablamos de profesionalidad como criterio de calidad, entendemos que el personal que trabaja en estas escuelas, sobre todo en las públicas, debiera poseer la formación y cualificación establecida por ley, en muchas ocasiones, y dado que el personal existente lleva años en el servicio, no se les exige reciclaje ni cualificación académica acorde a las exigencias legales. Hay aún escuelas públicas municipales, cuyos profesionales aún no tienen la titulación mínima exigida. Ante este hecho consideramos necesario una revisión de la cualificación y actualización del personal. Consideramos que la estabilidad es sinónimo de calidad en su servicio, a esta edades es importante que los niños dispongan de un referente estable, la inestabilidad del personal suele convertir a los centros en espacios de tránsito de profesionales que no llegan a establecer vínculos ni afecto con los niños por los cortos periodos de permanencia en los centros $(45 \%$ de las plantillas son trabajadores eventuales).

En lo referente al proyecto educativo común, hemos de indicar que en general lo poseen. Aquellos centros que trabajan con PEC, con programaciones de aula, cumplen con los objetivos planificados. Es notorio resaltar también que todo el trabajo de intervención temprana (atención a las 
necesidades educativas), se llega a realizar con los niños que lo requieren, gracias a al proyecto común y a la adaptación que hacen en estas escuelas y que se recogen en sus PEC. Además de esto, los niños de escuelas infantiles en las que se trabaja con programaciones, rutinas, idiomas, etc., manifiestan más competencias y habilidades que otros que no han sido escolarizados durante este primer ciclo de educación infantil, o que lo han estado en escuelas infantiles privadas. Son incluso los maestros de los CEIP, los que al recibir a los alumnos de estas escuelas infantiles municipales, dan las gracias por el trabajo adelantado que tienen al comienzo del curso, y por las normas, rutinas, control de hábitos, etc.

La cocina propia o no de una escuela infantil, suele ser el hándicap más costoso de superar, para considerarlo como criterio de calidad, sobre todo de cara a que un padre elija o no este servicio. Últimamente y con los sistemas de control de calidad que existen, en las escuelas infantiles sobre todo públicas, los llamados APPCC (índices y puntos de control críticos, que son llevados a cabo de manera continua y rigurosa, tanto con cocina propia como con catering), exigen a los centros que se reciclen anualmente, por lo menos al personal educativo, en materia de manipulación de alimentos. Puntualmente se recogen muestras de la comida para ser analizadas, se recogen muestras de las manos de los usuarios de la cocina, para detectar posible proliferación de bacterias, entre otras muchas cosas. Todo esto para intentar controlar cada vez más las toxiinfecciones alimentarias. A pesar de entender, de forma lógica, que lo mejor sería la cocina casera, hemos visto como casi la mitad de las escuelas usan catering, y la otra mitad cocina propia. La decisión del uso de catering, es la intención incesante de los consistorios municipales, que cada vez intentan descentralizar los servicios propios. Les resulta más fácil delegar el servicio a una empresa externa para evitar así, la responsabilidad de toxiinfección alimentaria en los niños.

En las escuelas infantiles públicas, casi todas respetan el número de niños por aula, es decir, las ratios establecidas por decreto.

Por todo lo dicho hasta ahora y a la luz de los resultados, consideramos que es posible elaborar una propuesta de mejora en las escuelas infantiles municipales, de acuerdo a los siguientes aspectos:

- $\quad$ Ya que partimos de la idea de que esta etapa, tal y como recoge la LOE, es una etapa educativa más, sería conveniente que la Consejería de Educación asumiera la gestión y control de la misma en su primer ciclo.

- $\quad$ Puesto que hay suficiente demanda de este tipo de escuelas y teniendo incluso muchas veces listas de reserva de admitidos, se debería promover un aumento de la oferta de plazas, se hace necesario que las administraciones locales comiencen a ofrecer subvenciones destinadas promoción y creación de nuevas escuelas municipales. 
- La inspección educativa ha de ejercer mayor control sobre la cualificación profesional del personal y sobre el funcionamiento y gestión de las escuelas infantiles, sobre todo las de ámbito privado, para que se lleve a cabo un control efectivo y real con plazo para el cumplimiento de lo exigido en la normativa reguladora.

- Mejorar la coordinación entre los dos ciclos de infantil de educación infantil, para mejorar los procesos de transición a la educación obligatoria, (comunicación y coordinación de las escuelas infantiles públicas y los colegios de la zona).

- Mejora de la implicación de todos los agentes educativos que participan de las escuelas infantiles municipales.

\section{References:}

1. Abudinén, G., Soto, D., y Rodríguez-Morales, A. J. (2012). Importancia de fomentar la investigación científica en salud pública desde pregrado. Salud pública de México, 54(5), 459-462.

2. Azkona, J. M., y Hoyuelos, A. (2015). Reflexiones sobre la calidad en las escuelas infantiles. Tarbiya, Revista de Investigación $e$ Innovación Educativa, (42). Recuperado de: https://revistas.uam.es/tarbiya/article/view/273/259

3. BOC, 107 (2017). Resolución de 26 de mayo de 2017, por la que se establece el calendario escolar y se dictan instrucciones para la organización y desarrollo de las actividades de comienzo y finalización del curso 2017/2018, para los centros de enseñanzas no universitarias de la Comunidad Autónoma de Canarias.

4. BOC, 143 (2010). Reglamento Orgánico de Centro (ROC) Decreto $81 / 2010$, de 8 de julio, por el que se aprueba el Reglamento Orgánico de los centros docentes públicos no universitarios de la Comunidad Autónoma de Canarias.

5. BOC, 203 (2008). Decreto 201/2008, de 30 de Septiembre, por el que se establecen los contenidos educativos y los requisitos de los centros que imparten el primer ciclo de Educación Infantil en la Comunidad Autónoma de Canarias.

6. BOE, 307 (2002) Ley Orgánica de calidad de la educación (LOCE), de 23 de diciembre.

7. BOE, 106 (2006). Ley Orgánica de Educación (LOE), de 3 de mayo.

8. BOE, 238 (1990). Ley Orgánica de ordenación general del sistema educativo (LOGSE), de 3 de octubre.

9. Educación \& ciudadanía (2008). Monográfico Fundación Educación y Ciudadanía (1). Recuperado de: http://www.feteugt.es/data/Upload/SINfundacion_infantil.pdf

10. Pérez-Jorge, D., Barragán-Medero, F. \& Molina-Fernández, E. 
(2017). A Study of Educational Programmes that Promote Attitude Change and Values Education in Spain, Asian Social Science, 13(7), 112-130.

11. Pérez-Jorge, D. (2010). Actitudes y concepto de la diversidad humana: Un estudio comparativo en centros educativos de la isla de Tenerife (Tesis doctoral). Universidad de La Laguna, Canarias, España.

12. Pérez-Jorge, D. (2010b). El profesor motivador: El profesor que estimula e implica a los alumnos en proyectos para el desarrollo de la competencia cultural y artística. En O. Alegre, O. (Ed.), Capacidades docentes para atender a la diversidad (pp.139-153). Sevilla, España: MAD.

13. Pérez-Jorge, D. y Rodríguez, M. C. (2012). Actitudes de los maestros hacia las necesidades especiales de los alumnos. En O. Alegre, (Ed.), Investigación sobre competencias y tecnología para la inclusión y la interculturalidad (pp.180-196). Madrid, España: Arial.

14. Santín, D., Balart, P., y Cabrales, A. (2015). Reflexiones sobre el sistema educativo español. Madrid: Centro de Estudios Ramón Areces.

15. Zabalza, M. A., y Beraza, M. Á. Z. (1996). Calidad en la educación infantil. Madrid: Narcea Ediciones. 